\title{
Língua Wai Wai e língua Portuguesa no contexto urbano: a situação sociolinguística dos Wai Wai que migraram para Santarém/PA
}

\author{
Wai Wai and Portuguese languages in the urban \\ context: the sociolinguistic situation of the Wai Wai who \\ migrated to Santarém/PA \\ Denize de Souza Carneiro ${ }^{1}$ \\ https://orcid.org/0000-0003-0980-8359 \\ Klyssia Cristhie Castro Gama ${ }^{2}$ \\ https://orcid.org/0000-0003-1065-7105
}

DOI: $10.26512 /$ rbla.v12i1.30145

Recebido em abril/2020 e aceito em maio/2020

\section{Resumo}

Este trabalho apresenta os resultados de uma pesquisa realizada com o objetivo de levantar dados sociolinguísticos dos Wai Wai que migraram para Santarém/PA, analisando a situação de monolinguismo, bilinguismo e/ou plurilinguismo desses indígenas, o valor funcional e a atitude dos falantes em relação às línguas de seu repertório. O estudo foi realizado sob o enfoque teórico e metodológico da Sociolinguística Qualitativa, a partir de pesquisa bibliográfica e, principalmente, por meio de pesquisa de campo. Os resultados mostraram que fazem parte do repertório linguístico dos Wai Wai sete línguas: Wai Wai, Hixkaryána, Xeréw, Katuéna, Tyrió, Português e Inglês; com diferentes graus de habilidades quanto ao entendimento, à fala, à leitura e à escrita. Constatou-se também, que ainda que a língua Wai Wai permaneça viva nas famílias dos participantes da pesquisa, já começa a perder função em domínios importantes que antes lhe pertenciam, como no domínio do lar.

Palavras-chave: Sociolinguística qualitativa. Povo Wai Wai. Bilinguismo. Valor funcional e atitude linguística.

\section{Abstract}

This work presents the results of a research carried out with the objective of collecting sociolinguistic data of the Wai Wai who migrated to Santarém/PA, analyzing their degree

1 Linguista, professora Assistente II na Universidade Federal do Oeste do Pará (UFOPA). Campus Rondon, cidade de Santarém/PA. Programa de Letras e Formação Básica Indígena. E-mail: denize.carneiro@ufopa.edu.br.

2 Graduada em Letras, Língua Portuguesa pela Universidade Federal do Oeste do Pará (UFOPA). E-mail: klyssia.gama@gmail.com. 
of monolingualism, bilingualism and/or plurilingualism, the functional value and attitudes towards the languages of their repertoire. The study was carried out under the theoretical and methodological approach of Qualitative Sociolinguistics, based on bibliographic research and, mainly, through field research. The results showed that seven languages belong to the linguistic repertoire of the Wai Wai: Wai Wai, Hixkaryána, Xeréw, Katuéna, Tyrió, Portuguese and English; with different degrees of skills in understanding, speaking, reading and writing. It was also found that, although the Wai Wai language remains alive in the families of the research participants, it is beginning to lose its function in important domains that previously belonged to it, such as the home domain.

Keywords: Qualitative sociolinguistics. Wai Wai people. Bilingualism. Functional value and linguistic attitude.

\section{Introdução}

O atual cenário das línguas indígenas no Brasil e no mundo não é muito promissor para a sobrevivência dessas línguas, principalmente no espaço urbano.

Conforme o Programa das Nações Unidas para Assentamentos Humanos (ONU-Habitat), em muitos países, mais da metade da população indígena reside em área urbana. Na América Latina, dados do ano 2000 indicam a existência de 30 milhões de indígenas na região, sendo que cerca de 12 milhões residem em área urbana (Andrade et al. In.: Comissão Pró-Índio 2013).

No Brasil, a população indígena em todo território nacional soma 896,9 mil pessoas, sendo que desses, 36,2\% residem na área urbana e 63,8\% na rural (IBGE 2012). Esse Censo também revelou dados preocupantes sobre a situação sociolinguística dessas línguas. Mostra que a percentagem de indígenas falantes de português é de 75\%, dentro e fora de Terras Indígenas, incluindo bilíngues e monolíngues. Apenas em algumas regiões, crianças e idosos tendem a ser monolíngues em língua indígena. $\mathrm{O}$ índice de monolinguismo em português dos indígenas residentes fora da Terra Indígena é 87\%. E do total de pessoas que se declaram ou se reconhecem como indígenas somente $37 \%$ afirmam ser falantes de língua indígena (Santos 2016).

Considerando um cenário mundial, a ONU-Habitat identifica que a urbanização dos povos indígenas é resultado de dois processos principais, que também ocorreram e ainda ocorrem no Brasil: o crescimento das cidades, que alcança as terras indígenas e as englobam na área urbana; e a migração dos indígenas para as cidades (Idem).

A migração para ambientes urbanos pode ser voluntária ou forçada. Ou seja, a migração pode ocorrer por desejo dos indígenas ou pode ser motivada por dificuldades de sobrevivência na Terra Indígena, tais como a falta de alimentos, doenças e outros. Esses fatores levam os indígenas ao impasse de tentar enfrentar a insegurança e as carências de sobrevivência na terra de origem ou migrar. Portanto, são necessárias Políticas Públicas para assegurar meios 
de vida tanto para os indígenas na zona urbana quanto para os que vivem na Terra Indígena. As ações visando melhorar as condições de vida dos índios na cidade devem se somar e não substituir aquelas destinadas a garantir todas as condições para a sua reprodução física e cultural, considerando os costumes e tradições, conforme vivenciado na terra de origem. Sem isso, a migração poderá ser compulsória e violadora de direitos e não fruto de livre escolha (Andrade et al. In: Comissão Pró-Índio 2013).

De acordo com estudos de Laura Ponte (2009 In: Comissão Pró-Índio 2013), as principais motivações para migração de indígenas para Belém/PA são a busca por uma melhor educação escolar, o que explica não apenas o deslocamento das famílias para as cidades, mas também a permanência nelas. Tal motivação soma-se à busca por melhores condições vida, que se almeja obter por meio de trabalho assalariado ou por casamento com membros da sociedade nacional. Outras motivações para a migração são problemas familiares ou conflitos entre os membros de uma aldeia. Essas motivações não são exclusivas para migração de indígenas para a cidade de Belém, ocorrem em outros lugares do Brasil, como no caso de Santarém.

Mas é o acesso à educação um dos principais motivos para migração, pois em muitas aldeias não há oferta de Ensino Médio e muito menos de Ensino Superior. Ademais, a partir Constituição de 1988, a qual prevê a consolidação de uma Política Pública de educação escolar diferenciada para povos indígenas, desencadeou-se a expansão de processos de escolarização nas aldeias, criando demanda por qualificação de professores aptos a trabalhar em seus territórios. Essa demanda fez crescer o interesse dos indígenas pelo Ensino Superior em todo Brasil. E com a aprovação da Lei de Cotas, em 2012, que tornou obrigatória, em todas as Universidades Federais, a reserva de vagas para populações historicamente excluídas (como indígenas e quilombolas), o ingresso dos indígenas no Ensino Superior passou a ocorrer com regularidade em algumas universidades. Foi a partir dessa lei que a presença indígena nas universidades de Santarém tornou-se mais perceptível.

Para Santos (2016), a maneira conflituosa e compulsória com as quais as línguas indígenas foram postas em contato com a língua portuguesa, já é suficiente para motivar pesquisas sociolinguísticas, tendo como foco compreender o "contato linguístico" ou o "conflito etno-linguístico" "existente.

3 As expressões línguas em contato e em situação de conflito concebem diferentes relações linguísticas. A relação de conflito é vista mais como "a coexistência antagônica de duas ou mais línguas em um espaço geossocial", indicando outros conflitos, que seriam mais conflitos de poder; já a expressão línguas em contato, segundo concepção de Weinreich (1953 In. Franceschini 2011), refere-se mais a situações "harmônicas" entre mais de uma língua falada em determinado espaço geossocial. Porém, essa última noção é criticada, uma vez que, em geral, camufla a realidade das línguas, que muitas vezes é a de um processo de substituição da língua dominada (Idem). Considerando essas noções, pode-se dizer que, 
Pesquisas dessa natureza também são importantes para contribuir com a vitalidade dessas línguas e para previsões teóricas sobre o risco de morte de línguas com poucos falantes. Além disso, esta pesquisa se justifica pelo fato de não existirem pesquisas deste cunho em Santarém (Pará), cidade que concentra grande diversidade linguística e cultural.

Assim, objetiva-se apresentar neste artigo os resultados de uma pesquisa que analisou os seguintes aspectos sociolinguísticos dos Wai Wai que migraram para Santarém: o nível de bilinguismo dos membros do grupo; o Valor funcional de suas línguas - bilinguismo social; continuidade ou descontinuidade na transmissão da língua indígena e a atitude dos falantes com relação às línguas que compõem seu repertório linguístico. Espera-se poder dar visibilidade quanto à situação da língua Wai Wai na cidade de Santarém e que os resultados possam servir de instrumento para ações de valorização e fortalecimento das línguas indígenas no espaço urbano.

Esta pesquisa foi desenvolvida em duas etapas: pesquisa bibliográfica e pesquisa de campo. Na primeira, buscou-se o embasamento teórico para este estudo sobre o valor funcional de uma língua e nível de bilinguismo. Além dos autores sobre questões teóricas, fez-se levantamento bibliográfico de literaturas referentes ao povo Wai Wai, para obter informações sobre dados histórico-geográficos, culturais e linguísticos desse povo. A segunda etapa foi destinada à pesquisa de campo, etapa de fundamental importância para esta pesquisa, realizada a partir de entrevistas aos indígenas, utilizando questões semiestruturadas. Para análise dos dados, levamos em conta as seguintes variáveis: sexo; idade; constituição familiar; tempo de residência em Santarém e escolaridade.

\section{Orientação teórica}

Este trabalho foi desenvolvido à luz das reflexões teóricas da Sociolinguística, uma área da linguística que se preocupa com o estudo da relação "entre a língua que falamos e a sociedade em que vivemos" (Coelho et al. 2015, 13).

Sob essa perspectiva Castilho (1998) citado por Lima et al. $(2010,13)$ concebe língua como "uma realidade sócia historicamente construída pelos sujeitos/interlocutores", ou seja, é uma atividade social, é enunciação, cujo uso é concreto e historicamente situado e envolve sempre um locutor e um interlocutor, situado num tempo e num espaço determinado.

Tanto essa concepção de língua quanto o escopo de estudo da sociolinguística é compartilhado com outras áreas de conhecimento da linguística, por exemplo,

desde a colonização portuguesa até aos dias atuais, as "relações"e entre as línguas indígenas brasileiras e o português "podem ser caracterizadas muito mais como situações de conflito do que situações de contato de línguas", visto que ao longo da história as línguas indígenas foram sendo substituídas pela língua majoritária, que goza de poder e prestígio. 
a Linguística Histórica, a Análise do Discurso, a Linguística Enunciativa, por isso é adequado dizer que a sociolinguística não é "a" área que estuda a relação entre língua e sociedade, mas é "uma" das áreas que se dedica ao estudo da língua no contexto social (Coelho et al. 2015, 13).

Para Pagotto $(2006,52)$ a sociolinguística desenvolve tal estudo buscando os lugares de intersecção entre o mundo social e a dimensão linguística, cuja definição é feita a partir do "funcionamento social ou do linguístico", sob diferentes linhas de pensamento, destacando-se: (1) a Teoria da variação e mudança linguística; (2) a Etnografia da fala e a (3) Sociologia da linguagem. Todas elas estudam o funcionamento da língua em seu contexto social, porém, com enfoques distintos.

A Teoria da variação e mudança linguística e a Etnografia da fala tem como objetivo comum nos seus estudos compreender o funcionamento da língua e como este é afetado pela sua relação com a sociedade. Enquanto a teoria da variação e mudança investiga as alterações de que maneira o sistema linguístico é afetado pelas relações sociais, no seu núcleo gramatical, levando em consideração o plano da cena enunciativa e também as organizações em classes e grupos sociais; a etnografia da fala terá como foco o conhecimento das regras sociais que regem o emprego das normas linguísticas, como parte do funcionamento social. Ou seja, ambas estudam a relação entre língua e sociedade, mas o meio de interseção entre esses estudos é distinto: a etnografia da fala "parte do social para o linguístico"; já a teoria da variação e mudança "parte do linguístico" para o social. Por sua vez, a Sociologia da linguagem (ou Sociolinguística qualitativa), que estuda as relações "maiores" entre língua e sociedade, busca entender como uma língua se espalha por uma determinada comunidade e quais as relações entre esse espalhamento e as estruturas de poder.

É em função desses diferentes enfoques da sociolinguística que John Gumperz (In: Bortoni-Ricardo 2014, 13) distingue aspectos analíticos micros e macros, ou seja, para ele há uma Micro e uma Macrosociolinguística. Na Microsociolinguística estão inclusos os estudos da Etnografia da Fala e da Teoria da Variação e Mudança Linguística. Já na Macrosociolinguística estão comtemplados os estudos da Sociologia da linguagem que acolheu temas mais amplos da relação língua e sociedade, como: "multilinguismo, bilinguismo, diglossia, atitudes linguísticas, manutenção e mudança linguística, bem como planejamento e estandardização da língua vernácula".

Dentre essas distintas linhas de pensamento, esse estudo foi realizado com base no enfoque teórico-metodológico da Sociologia da Linguagem (ou Sociolinguística Qualitativa). 


\subsection{O bilinguismo individual e o bilinguismo social: algumas noções}

Abordar a questão do bilinguismo não se configura em uma tarefa fácil devido a existência de diversas abordagens e critérios para sua concepção. Por muito tempo essa situação linguística foi tratada somente como uma característica do comportamento linguístico individual. É a partir dos trabalhos desenvolvidos na área de sociolinguística que ele passa a ser analisado também como um fenômeno social, a partir de pesquisas em comunidades bilíngues.

Assim, o estudo aqui apresentado foi realizado com base nas reflexões de autores que abordam o assunto na perspectiva do bilinguismo individual e na perspectiva do bilinguismo social. Ou seja, tratamos o bilinguismo ("domínio" de duas línguas) e o plurilinguismo (“domínio" de mais de duas línguas) em contraposição ao conceito relativo de monolinguismo ("domínio" de uma língua), no âmbito de dois pontos de vista: pessoal/individual e coletivo/social.

De Heredia (1989), no âmbito dos seus trabalhos sobre as habilidades linguísticas individuais de imigrantes estrangeiros em Paris, classificou o bilinguismo individual em "bilinguismo passivo" e "bilinguismo ativo". Também apresentou uma reflexão sobre o comportamento linguístico dos falantes, no que tange atitudes de valorização das línguas que compõem o seu repertório linguístico.

Quando os indivíduos compreendem duas línguas de seu repertório linguístico, mas falam apenas uma, encontram-se em uma situação de bilinguismo passivo. Quando os indivíduos não só compreendem duas línguas de seu repertório linguístico, como as falam (de forma fluente), eles se encontram numa situação de bilinguismo ativo.

Essa classificação de De Heredia tem relação com a perspectiva funcional de bilinguismo apresentada por Grosjean (2008), que entende que haverá bilíngue mais ou menos fluente em uma língua do que em outra. Para ele, as habilidades linguísticas de entender, falar, ler e escrever irão se desenvolver a partir da necessidade de comunicação, o que leva a diversas situações de bilinguismo, por exemplo, pessoa com proficiência de fala, leitura e escrita em duas línguas; pessoa com proficiência de fala, mas não de escrita em uma das línguas; bilíngue que fala bem em uma língua e com dificuldade em outra; bilíngue que fala e entende uma língua e apenas entende na outra. Mediante a isso, Grosjean considera uma pessoa bilíngue aquela que apresentar uma das quatro habilidades linguísticas.

Quanto à atitude de valorização linguística, segundo De Heredia (1989) tem a ver com a ligação que os locutores emigrados mantêm com sua língua e que se manifesta pelo uso que fazem dela entre familiares e amigos e por sua transmissão às crianças, o que está evidentemente relacionada com as atitudes de valorização que desenvolvem em relação aos dois países, no caso deste 
estudo, em relação à Terra Indígena e a cidade, representados simbolicamente pelo uso de sua língua (Heredia,1989, 178), o que procuramos observar na análise sociolinguística dos Wai Wai em Santarém.

$\mathrm{Na}$ perspectiva bilinguismo social, Fishman (1964) investiga os padrões sociais do uso das variedades linguísticas de uma dada "comunidade de fala", isto é, quando os membros de um agrupamento social têm pelo menos, em comum, uma variedade linguística, assim como as normas de seu emprego.

No primeiro momento de sua análise chamada de "sociolinguística descritiva", procura descrever os padrões de organização social existentes no uso das línguas da comunidade de fala e do comportamento dos falantes em relação a estas línguas, considerando que as comunidades de fala nem sempre manifestam o mesmo uso ou o mesmo comportamento. Para isto, busca-se compreender quais os fatores que condicionam as diferenças de mudanças na organização do uso da língua e no comportamento em relação à língua. Para essa descrição procura-se responder as seguintes indagações: quem fala, ou escreve, que língua, a quem, quando e para que fim? Aqui, o objetivo é descrever o modo como e porque esse padrão muda ou permanece instável. Quer dizer: cabe mostrar a natureza sistemática das alternâncias entre as variedades linguísticas apresentadas pelos indivíduos que compõe uma comunidade de fala que compartilham um mesmo repertório linguístico.

No segundo momento, chamadode "sociolinguística dinâmica" dalinguagem, a investigação consiste em identificar os fatores que motivam as diferenças de mudança e de organização social do uso da língua e do comportamento em relação à língua, seletivamente, em uma mesma comunidade de fala. A alternância entre variedades linguísticas não está restrita as comunidades de fala plurilíngues. Pode ocorrer em monolíngues, podendo alternar entre variedades de classes sociais, regionais e ocupacionais da mesma língua, que é definido por: quando dizer uma coisa e quando dizer a outra, no momento de interação dos indivíduos que compreendem quando é ou não adequado o uso de determinada variedade linguística, fenômeno caracterizado como mudança situacional.

Embora o bilinguismo seja uma habilidade linguística individual, segundo Fishman, a escolha de uma ou outra variedade e o seu uso adequado não ocorre ao acaso, mas é determinado sócio-culturalmente. A escolha da variedade depende da "situação", sendo esta definida como: "a co-ocorrência de dois (ou mais) interlocutores mutuamente relacionados de uma maneira determinada, comunicando sobre um determinado tópico, num determinado contexto" (1974, 29).

A mudança de situação pode acarretar vários fenômenos, como explica o autor: 
Uma mudança de situação pode exigir uma mudança na variedade linguística. Uma mudança na variedade linguística pode indicar uma mudança na relação entre os co-membros de um complexo social, ou uma mudança no tópico e propósito de sua interação, ou uma mudança na intimidade ou local dessa interação.

Fishman agrupa as situações que demandam uma mesma variedade linguística em classes de situações e a estas chama de "domínio". Os domínios também podem ser definidos sócio-culturalmente como, por exemplo, o domínio do lar, da religião, da educação e do trabalho, os quais podem exigir ou não uma ou outra variedade.

A "competência comunicativa sociolinguística", no que diz respeito ao que é ou não adequado na língua, é adquirido de forma inconsciente pelos membros de uma comunidade, mesmo assim, os falantes sabem adequar o uso das variedades de acordo com os domínios. Quem é externo à comunidade é que deverá descobrir as normas que regem os usos das variedades.

Nesse estudo do bilinguismo social, Fishman caracterizou dois tipos de bilinguismo: o "bilinguismo estável" e o "instável".

Se a diferenciação funcional das variedades do repertório linguístico dos falantes estiver sendo sistemática e amplamente mantida, significará que essas comunidades estão mantendo o seu padrão sociolinguístico e encontram-se numa situação de bilinguismo estável, isto é, as línguas mantêm seus próprios domínios sociais, sem que uma das línguas ocupe os domínios da outra, mantêmse, portanto, funcionalmente distintas.

Porém, se, ao contrário, a distribuição funcional das línguas não estiver bem definida e houver flutuação entre os domínios de uma ou outra variedade, estaremos diante de uma situação de bilinguismo instável, isto é, uma das línguas estará perdendo seu valor funcional, deixando de ser falada em domínios sociais que antes lhe pertenciam e, portanto, estará perdendo espaço na comunidade de fala, o que em muitos casos poderá levar a uma situação de monolinguismo.

Foi a partir dessas reflexões teóricas sobre o bilinguismo individual e social que descrevemos e analisamos a situação sociolinguística do povo Wai Wai em Santarém, pois as mesmas servem também para caracterizar o plurilinguismo.

\section{O povo Wai Wai}

Os Wai Wai são povos de língua e cultura Karíb. O etnômino Wai Wai, segundo os Wapixána, significa ao pé da letra "farinha branca" ou "tapioca" e tem sido usado por eles para se referir ao grupo em estudo porque os integrantes desse grupo foram considerados de pele mais clara (Queiroz 2008).

De acordo com Queiroz (2015) Wai Wai é um termo genérico para designar vários "subgrupos" indígenas que habitam uma região que vai do Sul da Guiana 
(rio Essequibo), passa pelo Leste de Roraima (rios Jatapu e Anauá) e chega ao Noroeste do Estado do Pará (rio Mapuera).

O pertencimento de cada "subgrupo" indígena a uma ou outra etnia pode ser melhor compreendido a partir de razões sociológicas, cosmológicas e históricas. Nas razões históricas há circunstâncias particulares de intervenção devido aos agentes da sociedade ocidental, em especial a intervenção missionária, que teve papel crucial na formação e na "invenção" das "unidades culturais e sociais", denominadas Wai Wai e Katxuyána (Queiroz 2015).

Cronistas, missionários, antropólogos e indigenistas que percorreram e descreveram a região usaram diferentes categorias para designar tais "grupos" ou "subgrupos". Todas elas guardam a dificuldade em circunscrever a unidade social à que se quer fazer referência. Unidades sociais são compreendidas por Queiroz, como associações provisórias fortemente marcadas pelo fator migração, intercasamentos e locais de moradia. Neste trabalho será usado a categoria "povo" para se referir aos grupos indígenas por achar que ela está mais próxima ao conceito nativo de yana ou yenna, um coletivo de pessoas (conforme a perspectiva desses povos) e "etnia" para um subgrupo.

Atualmente, ainda é importante tentar desenhar um quadro da distribuição espacial dessas unidades sociais, a partir de critérios linguísticos, culturais e de proximidades geográficas. Frikel, citado por Queiroz (2015), propôs a classificação dessas unidades sociais em três grandes complexos culturais, todos eles filiados a família linguística Karíb, com exceção de uma pequena área, às margens do rio Mapuera, habitada originalmente pelos Mawayánas, falantes da língua de mesmo nome pertencente à família Aruák. Tais complexos foram denominados por: Complexo Parukuto-Charuma, Complexo Warikyána e Complexo Pianokoto-Tyrió. Desses complexos, interessa-nos o complexo Parukuto-Charuma por ser composto pelos Wai Wai, Hixkaryána, Xeréw, Mawayána, Karapawyána, Tunayána, Parukuto e Katuéna.

\subsection{A localização e população dos Wai Wai}

No Brasil, o povo Wai Wai vive na chamada Amazônia Setentrional, em Três Terras Indígenas: na Terra Indígena Nhamundá-Mapuera; na Terra Indígena Trombetas-Mapuera e na Terra Indígena Wai Wai.

A primeira Terra Indígena (T.I.), a Nhamundá-Mapuera, fica localizada nos estados do Amazonas e do Pará. Sua área territorial soma um total de 1.049.520 hectares, composta por cinco aldeias: Nhamundá, Mapuera, Tamiurú, Pomkurú e Bateria. A segunda T.I., a Trombetas-Mapuera, localiza-se no extremo Sul de Roraima, no extremo Norte do Amazonas e a Noroeste do Pará, com uma área de 3.970.898 hectares e é composta por seis aldeias: Kwanamary, Inajá, Placa, Cobra, Jatapuzinho e Fatual. Estas duas Terras Indígenas são denominadas terras dos Wai Wai (Cardozo; Vale Jr. 2012). A maioria das aldeias está localizada às 
margens do Rio Mapuera, afluente formador do Rio Trombetas. Para ter acesso às aldeias deve-se viajar por esse rio. Porém, a viagem é um tanto desafiadora, pois, tal rio contém grande número de rochas e cachoeiras que tornam o tráfego difícil, principalmente no período de estiagem. São 82 cocheiras na extensão do rio, sendo as principais: Porteira, Escola, Paraíso, Égua, Caraná. Somente a aldeia Mapuera permite, além do acesso fluvial, o acesso por pequenas aeronaves, já que conta com uma pequena pista de pouso (Cardozo; Vale Jr. 2012).

De acordo com dados do IBGE, a população Wai Wai nas TIs NhamundáMapuera e Trombetas-Mapuera totaliza quase 3.000 pessoas, assim distribuída: na TI Nhamundá-Mapuera vivem aproximadamente 2.218 pessoas; e na TI Trombetas-Mapuera vivem 416 pessoas.

A terceira Terra Indígena, a Wai Wai, situa-se no Estado de Roraima, segundo dados do Instituto Socioambiental ${ }^{4}$, foi homologada em 24 de junho de 2003 e atualmente conta com uma população de 365 pessoas.

\subsection{A língua}

A classificação genética das línguas indígenas brasileiras, apresentada pelo linguista Aryon Dall'Igna Rodrigues (1986), segundo o qual, há, no país, famílias linguísticas ${ }^{5}$ que podem ser divididas em dois troncos linguísticos o tronco Tupí e o tronco Macro-Jê -, duas famílias maiores - Karíb e Aruák -, 11 famílias menores - Arawá, Kadiwéw, Páno, Nambikwára, Txapakúra, Katukína, Mura-Pirahã, Aruá, Makú, Tukáno, Yanomámi -, e sete línguas isoladas - Tikúna, Aikaná, Kwazá, Jabutí, Kanoê, Mynký, Trumái, e Máku. As línguas isoladas são assim denominadas pelo fato de serem membros únicos de suas respectivas famílias genéticas.

É na família Karíb ${ }^{6}$ que se insere a língua Wai Wai, falada pelo povo de mesmo nome. Excluindo os troncos linguísticos, que são as famílias com maior profundidade temporal e diversidade genética, merecem destaque pelas suas respectivas diversidades internas as famílias Karib, Aruák e Pano. Conforme Carneiro e Peixoto $(2015,274)$ :

\section{In: https://terrasindigenas.org.br/pt-br/terras-indigenas/3900}

5 Familía Linguística é caracterizada por Rodrigues (2002, apud Carneiro e Peixoto 2015) como aquelas línguas que possuem a mesma origem, ou seja, se originaram da mesma língua mãe, mas que no decorrer do tempo se modificaram de diferentes maneiras. Os troncos, possuem uma afinidade genética mais distante no tempo e uma unidade mais ampla. Assim, um tronco linguístico é constituído de Famílias linguísticas, e as Famílias são constituídas de línguas irmãs.

6 Segundo Meira (2006) a denominação Karíb é em virtude de sua origem ancestral, isto é, por terem esses povos sido encontrados nas ilhas do Caribe, das Guianas e da Venezuela. 
[...] são as famílias Karib, Aruák e Pano as que apresentam maior diversidade linguística. A família Karib é constituída de 22 línguas, as quais são faladas por aproximadamente 37.500 mil pessoas, que vivem espalhadas em diversos estados do Brasil (Amapá, Roraima, Rondônia, Mato Grosso, Pará e principalmente no Amazonas) e também nas Guianas, na Venezuela e na Colômbia. A família Aruák é composta por 15 línguas e a população que a fala é de aproximadamente 46 mil pessoas, que também vivem em diversos estados da federação, particularmente nos estados do norte do país. A família Pano, assim como a Aruák, também é constituída por 15 línguas, porém apresenta uma população menor de falantes, aproximadamente 12 mil pessoas.

Conforme exposto na citação, a família Karib é constituída de 22 línguas, que são faladas por cerca de 38 mil pessoas, distribuídas em vários estados brasileiros - Amapá, Roraima, Rondônia, Mato Grosso, Pará e Amazonas, além das demais línguas Karíb que são faladas por povos que vivem nas Guianas, na Venezuela e na Colômbia.

A língua Wai Wai segundo Cardoso e Vale Jr. (2012), pode ser considerada uma língua franca, espécie de língua geral, usada como língua comum de grupos sociais que vivem na Terra Indígena Trombetas/Mapuera, principalmente na aldeia Mapuera/PA, e que falam, cada um, uma língua Karíb diferente.

\section{Resultados e reflexões}

Com base nas reflexões teóricas da sociolinguística qualitativa apresentamos a análise da situação sociolinguística de membros do povo Wai Wai que migraram para Santarém/PA. Os dados analisados foram obtidos a partir de entrevistas junto aqueles que aceitaram participar da pesquisa, num período de 8 meses. Para contextualizar e ajudar compreender tal análise, apresentamos também informações sobre os consultantes, como: sexo, idade, aldeia de origem, local de moradia em Santarém, processo migratório, motivos para a migração e situação socioeconômica.

\subsection{Os sujeitos da pesquisa}

Muito se questiona sobre os critérios de definição sobre quem seja o indígena hoje. Melatti (1994) na tentativa de "definir os índios com certa precisão" e para procurar distingui-los das outras populações que habitam a América apresenta alguns critérios, quais sejam: o racial, o legal, o cultural, o de desenvolvimento econômico e o de autoidentificação étnica ${ }^{7}$. Por ser o último critério considerado o mais satisfatório, esse foi o adotado para este trabalho, pois, nessa perspectiva, o que vai decidir se um determinado grupo de sujeitos "é indígena ou não,

7 Para maiores informações quantos aos critérios para definição do indígena, vide Melatti (1994). 
seja qual for a sua composição racial, estejam em que estado estiverem suas tradições pré-colombianas, é o fato de eles próprios se considerarem índios ou não e de serem considerados índios ou não pela população que os cerca". (Melatti 1994, 25-26).

Desse modo, os sujeitos dessa pesquisa são pessoas que se autoidentificam como sendo do povo Wai Wai e, assim são considerados pelos outros membros dessa população. Vale lembrar que o Povo Wai Wai é constituído de vários subgrupos que fazem parte do Complexo Parukuto-Charuma, constituído pelas etnias: Wai Wai ${ }^{8}$, Hexkaryana, Xeréw, Mawayana, Karapawyana, Tunayana, Parukuto e Katuéna, conforme Frikel (1970 apud Queiroz 2015).

De acordo com o critério aqui escolhido foram localizadas 23 pessoas do povo Wai Wai que migraram para Santarém, mas apenas 17 aceitaram participar da pesquisa, sendo 13 homens, na faixa etária de 24 a 36 anos de idade e apenas 04 mulheres, na faixa etária de 23 a 33 anos de idade.

Quase todos são estudantes da Universidade Federal do Oeste do Pará ${ }^{9}$, cujo ingresso deu-se a partir do Processo Seletivo Especial Indígena (PSEI/Ufopa), realizado desde 2010, garantindo o acesso dos povos indígenas em quase todos os cursos de graduação dessa universidade. Já foram realizados 10 processos seletivos, por meio dos quais mais de 500 indígenas tiveram seu ingresso na educação superior.

Porém, nota-se que cerca de $80 \%$ dos aprovados nesse processo seletivo são indígenas da região do Baixo rio Tapajós, de comunidades situadas nas proximidades de Santarém, que se autoidentificam como sendo das etnias: Arapiun, Borari, Jaraqui, Kumaruara, Munduruku, Munduruku Cara Preta, Maytapu, Tupinambá, Tapuia, Tapajó, Tupaiú, Arara Vermelha e Apiaká. Em geral, são "monolíngues" em língua portuguesa, consequência das políticas autoritárias do colonizador, baseadas no ideologema "uma nação, um povo, uma língua" (Bagno 2017:334). Os indígenas da Terra Indígena Munduruku (Alto Tapajós), das Terras Indígenas Trombetas-Mapuera/Nhamundá-Mapuera (Calha Norte) e Terra Indígena Andirá-Maraw que tem a língua do seu povo como primeira, por exemplo, Wai Wai, Munduruku e Sateré-Mawé, têm encontrado dificuldades para ingressar na instituição mesmo por meio de um processo seletivo especial que "seleciona" os candidatos a partir de um texto escrito em

8 Os membros entrevistados reconhecem que existe o Povo Wai Wai (formado por várias etnias) e a Etnia Wai Wai, que é um dos subgrupos desse povo.

9 A Universidade Federal do Oeste do Pará (UFOPA) é uma instituição multicampi, criada pela Lei ${ }^{\circ}$ 12.085, de 5 de novembro de 2009. Sua sede se localiza em Santarém, cidade polo da Região Oeste do Pará. Nos Campus Rondon, Amazônia e Tapajós, situados na sede, encontram-se a maioria dos cursos superiores ofertados pela instituição (cerca de 30), mas há também a oferta de cursos em seis cidades da região, a saber: Alenquer (1 curso), Itaituba (1 curso), Juruti ( 2 cursos), Monte Alegre (1 curso), Óbidos (1 curso) e Oriximiná ( 2 cursos). Em todos os cursos há reserva de vaga para as populações indígenas, no Processo Seletivo Especial Indígena (PSEI). 
português (uma "redação") e uma entrevista. De 2017 até o momento, período em que passamos a observar o ingresso dos indígenas nessa instituição, de um total de aproximadamente 60 vagas foram aprovados para os cursos da Ufopa/ Sede no máximo 4 indígenas Wai Wai, por processo. Diversas razões podem ser apontadas para esse resultado, mas acreditamos que uma avaliação qualificada do PSEI deva ser realizada, tendo em vista verificar como proporcionar maior acesso aos indígenas bilíngues e plurilíngues da área de abrangência da Ufopa.

As informações sobre os membros do povo em estudo, participantes da pesquisa, podem ser observadas no quadro 01, a seguir.

Quadro 01: Matriz dos consultantes do Povo Wai Wai em Santarém/PA

\begin{tabular}{|c|c|c|c|c|c|c|c|c|}
\hline Entrevistado & Sexo & Idade & Escolaridade & $\begin{array}{l}\text { Etnia } \\
\text { do pai }\end{array}$ & $\begin{array}{l}\text { Etnia } \\
\text { da mãe }\end{array}$ & $\begin{array}{c}\text { Etnia do } \\
\text { entrevistado }\end{array}$ & $\begin{array}{c}\text { Aldeia } \\
\text { de origem }\end{array}$ & $\begin{array}{l}\text { Bairro em } \\
\text { Santarém }\end{array}$ \\
\hline 01 & $\mathrm{~F}$ & 23 & $\begin{array}{l}\text { Superior - } \\
\text { cursando }\end{array}$ & Wai Wai & Wai Wai & Wai Wai & Mapuera/PA & Maicá-Vigia \\
\hline 02 & $\mathrm{~F}$ & 33 & $\begin{array}{l}\text { Superior - } \\
\text { cursando }\end{array}$ & Wai Wai & Wai Wai & Wai Wai & Mapuera/PA & Maicá-Vigia \\
\hline 03 & $\mathrm{~F}$ & 25 & $\begin{array}{l}\text { Superior - } \\
\text { cursando }\end{array}$ & Wai Wai & Wai Wai & Wai Wai & Mapuera/PA & Caranazal \\
\hline 04 & M & 30 & $\begin{array}{l}\text { Superior - } \\
\text { cursando }\end{array}$ & Wai Wai & Wai Wai & Wai Wai & Mapuera/PA & Caranazal \\
\hline 05 & M & 24 & $\begin{array}{l}\text { Superior - } \\
\text { cursando }\end{array}$ & Katuéna & Tunayána & Katuéna & Mapuera/PA & Aldeia \\
\hline 06 & M & 30 & $\begin{array}{l}\text { Superior - } \\
\text { cursando }\end{array}$ & Mawayana & Wai Wai & Wai Wai & Mapuera/PA & Alvorada \\
\hline 07 & M & 33 & $\begin{array}{l}\text { Superior - } \\
\text { cursando }\end{array}$ & Wai Wai & Mura & Wai Wai & Mapuera/PA & Caranazal \\
\hline 08 & M & 36 & $\begin{array}{l}\text { Superior - } \\
\text { cursando }\end{array}$ & Hixkaryána & Wai Wai & Wai Wai & Kwanamarí/PA & Caranazal \\
\hline 09 & M & 35 & $\begin{array}{l}\text { Superior - } \\
\text { cursando }\end{array}$ & Mawayána & Mawayána & Mawayána & Mapuera/PA & Caranazal \\
\hline 10 & M & 26 & $\begin{array}{l}\text { Superior - } \\
\text { cursando }\end{array}$ & Wai Wai & Katuéna & Wai Wai & Mapuera/PA & Caranazal \\
\hline 11 & M & 24 & $\begin{array}{l}\text { Superior - } \\
\text { cursando }\end{array}$ & Wai Wai & Mawayána & Wai Wai & Mapuera/PA & Caranazal \\
\hline 12 & M & 36 & $\begin{array}{l}\text { Superior - } \\
\text { cursando }\end{array}$ & Wai Wai & Wai Wai & Wai Wai & Kaximí /RR & Caranazal \\
\hline 13 & M & 26 & $\begin{array}{l}\text { Superior - } \\
\text { cursando }\end{array}$ & Mawayána & Wai Wai & Wai Wai & Mapuera/PA & Caranazal \\
\hline 14 & M & 31 & $\begin{array}{l}\text { Superior - } \\
\text { cursando }\end{array}$ & Hixkaryána & Hixkaryána & Hixkaryána & Mapuera/PA & Caranazal \\
\hline 15 & M & 28 & $\begin{array}{l}\text { Superior - } \\
\text { cursando }\end{array}$ & Hixkaryána & Wai Wai & Hixkaryána & Mapuera/PA & $\begin{array}{c}\text { Jardim } \\
\text { Santarém }\end{array}$ \\
\hline 16 & M & 29 & $\begin{array}{l}\text { Superior - } \\
\text { cursando }\end{array}$ & Wai Wai & Wai Wai & Wai Wai & Mapuera/PA & Maicá-Vigia \\
\hline 17 & $\mathrm{~F}$ & 31 & $\begin{array}{l}\text { Superior } \\
\text { Completo }\end{array}$ & Mawayána & Mawayána & Mawayána & Mapuera/PA & Caranazal \\
\hline
\end{tabular}

Fonte: as autoras com base na pesquisa realizada no âmbito desse trabalho. 


\subsection{A migração dos Wai Wai para Santarém}

A migração dos Wai Wai consultados para Santarém realizou-se de forma mais contínua a partir de 2012 até os dias de hoje. Tal migração ocorreu para $70,6 \%$ dos membros do povo de forma indireta, ou seja, antes de residir em Santarém viveram em outras cidades, particularmente, na cidade de Oriximiná/ PA, para cursarem o Ensino Médio. Já para 29,4\% a migração foi direta, isto é, os membros não viveram em outras cidades, migraram diretamente da aldeia para Santarém, trata-se dos indígenas 1, 2, 3, 13 e 16, conforme mostra o quadro 02 .

\section{Quadro 02: Migração para Santarém/PA}

\begin{tabular}{|c|c|}
\hline \multicolumn{2}{|r|}{ Processo migratório dos Wai Wai para Santarém } \\
\hline Consultante & Processo migratório \\
\hline 01 & Mapuera $\rightarrow$ Santarém (2017) \\
\hline 02 & Mapuera $\rightarrow$ Santarém (2013) \\
\hline 03 & Mapuera $\rightarrow$ Santarém (2015) \\
\hline 04 & Mapuera $\rightarrow$ Oriximiná $\rightarrow$ Mapuera $\rightarrow$ Santarém (2017) \\
\hline 05 & Mapuera $\rightarrow$ Oriximiná $\rightarrow$ Santarém (2015) $\rightarrow$ Mapuera $\rightarrow$ Santarém $(2018)$ \\
\hline 06 & Mapuera $\rightarrow$ Oriximiná $\rightarrow$ Mapuera $\rightarrow$ Santarém (2012) \\
\hline 07 & Mapuera $\rightarrow$ Oriximiná $\rightarrow$ Santarém (2012) \\
\hline 08 & Mapuera $\rightarrow$ Oriximiná $\rightarrow$ Mapuera $\rightarrow$ Kwanamari $\rightarrow$ Santarém (2017) \\
\hline 09 & Mapuera $\rightarrow$ Oriximiná $\rightarrow$ Mapuera $\rightarrow$ Santarém $(2013)$ \\
\hline 10 & Mapuera $\rightarrow$ Oriximiná $\rightarrow$ Mapuera $\rightarrow$ Santarém (2015) \\
\hline 11 & Mapuera $\rightarrow$ Oriximiná $\rightarrow$ Mapuera $\rightarrow$ Santarém (2017) \\
\hline 12 & Kaximi/RR $\rightarrow$ Boa Vista/RR $\rightarrow$ Manaus/AM $\rightarrow$ Mapuera $\rightarrow$ Santarém $(2018)$ \\
\hline 13 & Mapuera $\rightarrow$ Santarém (2014) \\
\hline 14 & Mapuera $\rightarrow$ Oriximiná $\rightarrow$ Mapuera $\rightarrow$ Santarém \\
\hline 15 & Mapuera $\rightarrow$ Oriximiná $\rightarrow$ Mapuera $\rightarrow$ Santarém (2018) \\
\hline 16 & Mapuera $\rightarrow$ Santarém (2013) \\
\hline 17 & Mapuera $\rightarrow$ Oriximiná $\rightarrow$ Santarém (2013) \\
\hline
\end{tabular}

Fonte: as autoras, com base na pesquisa realizada para esse trabalho.

As razões apresentadas para a migração são: fatores socioeconômicos, busca por melhores condições de vida, acesso aos serviços de saúde e, principalmente, acesso à Educação Básica e ao Ensino Superior, motivada por programas de acesso, em virtude da Lei das cotas, como o Processo Seletivo Especial Indígena (PSEI), realizado pela Universidade Federal do Oeste da Pará, que os Wai Wai participam há 8 anos. 


\subsection{Situação socioeconômica das famílias dos sujeitos da pesquisa}

A situação socioeconômica dos Wai Wai consultados é um tanto precária. Todos adquirem sua renda através de benefícios do governo como, Bolsa família e Auxílio Estudantil (por meio Programa de Bolsa Permanência do Ministério da Educação e por auxílio permanência da própria universidade).

Quanto à moradia em Santarém, os Wai Wai moram em casas alugadas, situadas em bairros próximos à universidade onde estudam, como nos bairros Caranazal e Aldeia.

\subsection{Situação linguística dos Wai Wai residentes em Santarém}

De acordo com os dados obtidos na pesquisa fazem do repertório linguístico dos Wai Wai que residem em Santarém sete línguas, cinco línguas Karib, o português e o inglês, como mostra o quadro seguinte:

Quadro 03: Línguas que compõem o repertório linguístico Wai Wai em Santarém

\begin{tabular}{|c|c|c|c|c|c|}
\hline \multicolumn{5}{|c|}{ Línguas indígenas da família Karib } & $\begin{array}{c}\text { Língua } \\
\text { Germânica }\end{array}$ \\
\hline Wai & Hixkaryana & Katuena & Xerew & Tyrió & \\
\hline
\end{tabular}

Pode-se observar que o repertório linguístico desses indígenas é bastante diversificado. Todos os membros apresentam situações de bi- ou plurilinguismo nas línguas de seu repertório, como será descrito nas próximas seções.

\subsubsection{Nível de bi- e plurilinguismo e habilidades linguísticas}

Foram encontradas seis pessoas em situação de bilinguismo ativo em Wai Wai e Português, o que corresponde a 35,3\% do total dos 17 indígenas consultados na pesquisa; as outras pessoas encontram-se em situação de plurilinguismo e correspondem a $64,7 \%$ dos consultantes, conforme mostra o quadro 04 .

Quadro 04: Situação de bilinguismo e plurilinguismo

\begin{tabular}{|c|c|c|c|c|c|c|c|}
\hline \multicolumn{4}{|c|}{ Bilinguismo } & \multicolumn{4}{|c|}{ Plurilinguismo } \\
\hline Pessoas & $\%$ & Ativo & Passivo & Pessoas & $\%$ & Ativo & Passivo \\
\hline \multirow{5}{*}{6} & \multirow{5}{*}{$35,30 \%$} & \multirow{5}{*}{$\begin{array}{l}\text { Wai Wai } \\
\text { Português }\end{array}$} & \multirow{5}{*}{-} & 7 & $41,18 \%$ & $\begin{array}{l}\text { Wai Wai-Português- } \\
\text { Hixkaryána }\end{array}$ & - \\
\hline & & & & 1 & $5,8 \%$ & $\begin{array}{l}\text { Wai Wai-Poruguês- } \\
\text { Hixkaryána-Inglês }\end{array}$ & - \\
\hline & & & & 1 & $5,8 \%$ & Wai Wai-Português & Hixkaryána \\
\hline & & & & 1 & $5,8 \%$ & $\begin{array}{l}\text { Wai Wai-Poruguês- } \\
\text { Hixkaryána-Katuéna }\end{array}$ & Xeréw-Tyrió \\
\hline & & & & 1 & $5,8 \%$ & $\begin{array}{l}\text { Wai Wai-Poruguês- } \\
\text { Hixkaryána-Katuéna }\end{array}$ & Xeréw \\
\hline
\end{tabular}

Fonte: as autoras. 
É possível observar nos dados que todos os indígenas em situação de bilinguismo são ativos nas duas línguas do seu repertório. Já no caso de plurilinguismo, embora a maioria apresente plurilinguismo ativo nas línguas do seu repertório, vemos que há três situações de plurilinguismo passivo em: Hixkaryána / Xeréw-Tyrió / Xeréw. Nota-se também que 100\% dos indígenas apresentam domínio das línguas Wai Wai e Portuguesa e apenas 6,25\% apresenta domínio do inglês.

Embora os membros do povo Wai Wai apresentem situação de bilinguismo ou plurilinguismo nas línguas do seu repertório, existem diferentes graus de habilidades no uso dessas línguas, conforme Grosjean (1982), que entende que haverá bilíngue e plurilíngue mais ou menos fluente em uma língua do que em outra, como é possível observar no quadro 05.

\section{Quadro 05: Habilidades linguísticas dos Wai Wai que residem em Santarém}

\begin{tabular}{|c|c|c|c|c|c|c|c|}
\hline \multirow{2}{*}{ Consultante } & \multicolumn{7}{|c|}{ Línguas } \\
\hline & Wai Wai & $\begin{array}{c}\text { Língua } \\
\text { Portuguesa }\end{array}$ & Hixkaryána & Katuéna & Xeréw & Tyrió & Inglês \\
\hline 01 & $\begin{array}{l}\text { Fala bem; } \\
\text { Lê e Escreve } \\
\text { bem. }\end{array}$ & $\begin{array}{l}\text { Fala bem; Lê e } \\
\text { Escreve. }\end{array}$ & $\begin{array}{l}\text { Fala bem. Não lê e nem } \\
\text { escreve. }\end{array}$ & $\begin{array}{l}\text { Entende } \\
\text { e fala um } \\
\text { pouco. }\end{array}$ & $\begin{array}{l}\text { Apenas } \\
\text { entende. }\end{array}$ & $\begin{array}{l}\text { Apenas } \\
\text { entende. }\end{array}$ & - \\
\hline 02 & $\begin{array}{l}\text { Fala bem; Lê } \\
\text { e Escreve. }\end{array}$ & $\begin{array}{l}\text { Fala bem; Lê e } \\
\text { Escreve. }\end{array}$ & $\begin{array}{l}\text { Fala bem. Não lê e nem } \\
\text { escreve. }\end{array}$ & NHL & NHL & NHL & NHL \\
\hline 03 & $\begin{array}{l}\text { Fala bem; Lê } \\
\text { e Escreve. }\end{array}$ & $\begin{array}{l}\text { Fala bem; Lê e } \\
\text { Escreve. }\end{array}$ & $\mathrm{NHL}<>$ & NHL & NHL & NHL & NHL \\
\hline 04 & $\begin{array}{l}\text { Fala bem; Lê } \\
\text { e Escreve. }\end{array}$ & $\begin{array}{l}\text { Fala bem; Lê e } \\
\text { Escreve. }\end{array}$ & Entende e fala um pouco. & NHL & NHL & NHL & NHL \\
\hline 05 & $\begin{array}{l}\text { Fala bem; Lê } \\
\text { e Escreve. }\end{array}$ & $\begin{array}{l}\text { Fala bem; Lê e } \\
\text { Escreve. }\end{array}$ & NHL & $\begin{array}{l}\text { Entende e } \\
\text { fala. }\end{array}$ & NHL & NHL & NHL \\
\hline 06 & $\begin{array}{l}\text { Fala bem; Lê } \\
\text { e Escreve. }\end{array}$ & $\begin{array}{l}\text { Fala bem; Lê e } \\
\text { Escreve. }\end{array}$ & NHL & NHL & NHL & NHL & NHL \\
\hline 07 & $\begin{array}{l}\text { Fala bem; Lê } \\
\text { e Escreve. }\end{array}$ & $\begin{array}{l}\text { Fala bem; Lê e } \\
\text { Escreve. }\end{array}$ & NHL & NHL & NHL & NHL & NHL \\
\hline 08 & $\begin{array}{l}\text { Fala bem; Lê } \\
\text { e Escreve. }\end{array}$ & $\begin{array}{l}\text { Fala bem; Lê e } \\
\text { Escreve. }\end{array}$ & NHL & NHL & NHL & NHL & NHL \\
\hline 09 & $\begin{array}{l}\text { Fala bem; Lê } \\
\text { e Escreve. }\end{array}$ & $\begin{array}{l}\text { Fala bem; Lê e } \\
\text { Escreve. }\end{array}$ & Entende e fala um pouco. & NHL & NHL & NHL & NHL \\
\hline 10 & $\begin{array}{l}\text { Fala bem; Lê } \\
\text { e Escreve. }\end{array}$ & $\begin{array}{l}\text { Fala bem; Lê e } \\
\text { Escreve. }\end{array}$ & Entende e fala. & NHL & NHL & NHL & $\begin{array}{c}\text { Entende, } \\
\text { fala e lề } \\
\text { bem. }\end{array}$ \\
\hline 11 & $\begin{array}{l}\text { Fala bem; Lê } \\
\text { e Escreve. }\end{array}$ & $\begin{array}{l}\text { Fala bem; Lê e } \\
\text { Escreve. }\end{array}$ & Apenas entende. & NHL & NHL & NHL & NHL \\
\hline 12 & $\begin{array}{l}\text { Fala bem; Lê } \\
\text { e Escreve. }\end{array}$ & $\begin{array}{l}\text { Fala bem; Lê e } \\
\text { Escreve. }\end{array}$ & NHL & NHL & NHL & NHL & NHL \\
\hline 13 & $\begin{array}{l}\text { Fala bem; Lê } \\
\text { e Escreve. }\end{array}$ & $\begin{array}{l}\text { Fala bem; Lê e } \\
\text { Escreve. }\end{array}$ & NHL & NHL & NHL & NHL & NHL \\
\hline 14 & $\begin{array}{l}\text { Fala bem; Lê } \\
\text { e Escreve. }\end{array}$ & $\begin{array}{l}\text { Fala bem; Lê e } \\
\text { Escreve. }\end{array}$ & Entende e fala. & NHL & NHL & NHL & NHL \\
\hline 15 & $\begin{array}{l}\text { Fala bem; Lê } \\
\text { e Escreve. }\end{array}$ & $\begin{array}{l}\text { Fala bem; Lê e } \\
\text { Escreve. }\end{array}$ & $\begin{array}{l}\text { Fala e lê bem. } \\
\text { Escreve pouco. }\end{array}$ & $\begin{array}{l}\text { Fala e lê } \\
\text { bem. } \\
\text { Escreve } \\
\text { pouco. }\end{array}$ & $\begin{array}{l}\text { Apenas } \\
\text { entende. }\end{array}$ & NHL & NHL \\
\hline 16 & $\begin{array}{l}\text { Fala bem; Lê } \\
\text { e Escreve. }\end{array}$ & $\begin{array}{l}\text { Fala bem; Lê e } \\
\text { Escreve. }\end{array}$ & NHL & NHL & NHL & NHL & NHL \\
\hline 17 & $\begin{array}{l}\text { Fala bem; Lê } \\
\text { e Escreve. }\end{array}$ & $\begin{array}{l}\text { Fala bem; Lê e } \\
\text { Escreve. }\end{array}$ & Entende e fala um pouco. & NHL & NHL & NHL & NHL \\
\hline
\end{tabular}


Os dados mostram que todos os consultantes alegam que entendem, falam, leem e escrevem em Wai Wai e em Português. No que tange à língua Wai Wai dizem saber falar, ler e escrever bem, mas apenas a primeira consultante manifestou ótimo domínio na escrita, pois participou de projetos e atividades em sua aldeia que lhe proporcionaram exercitar a escrita em sua língua. Quanto ao português, todos dizem que sabem falar, ler e escrever o suficiente para a comunicação, mas apresentam certo receio em afirmar que possuem ótimo domínio nessa língua. Referindo-se à norma padrão do português, dizem que precisam melhorar suas habilidades nessa língua, especialmente na leitura e na escrita.

Os Wai Wai também apresentam habilidades linguísticas nas línguas Hixkaryána, Katuéna, Xeréw e Tyrió. A língua Hixkaryána faz parte do repertório de 11 pessoas, sendo que, dessas pessoas, 10 a falam e uma apenas a entende. A língua Katuéna faz parte do repertório de três pessoas que a falam. A língua Xeréw faz parte do repertório de duas pessoas e a língua Tyrió faz parte do repertório de uma pessoa. Nos dois casos são conhecedores passivos.

Além das línguas indígenas e da língua portuguesa, uma pessoa apresenta habilidade de fala, leitura e escrita na língua inglesa. Sabemos que na Terra Indígena desse povo diversos Wai Wai têm domínio do Inglês, devido aos muitos anos de convivência com missionários americanos da Unevangelized Fiel Mission (UFM), que viveram em suas aldeias evangelizando.

\subsection{Usos, valor funcional e atitude linguística}

Quanto ao uso das línguas nos diferentes domínios sociais, os membros do povo em estudo utilizam a língua Wai Wai no seio familiar, nas aldeias (na escola, na igreja), nos barcos de linha (para a área indígena) e, também, nas ruas das cidades por onde circulam para a comunicação entre si. No que tange à escrita dessa língua, ela costuma ser usada para comunicação via Facebook e também via WhatsApp.

As demais línguas Karib (Hixkaryána, Katwéna, Xeréw e Tyrió), também pertencentes ao repertório linguístico dos entrevistados, quase não são usadas na cidade, pois as pessoas que as falam encontram-se na Terra Indígena. Geralmente, o uso delas ocorre quando seus parentes falantes dessas línguas vêm à Santarém ou quando estes viajam para sua comunidade, no período de férias da universidade. Contudo, dependendo do interlocutor, essas línguas são usadas em conversas telefônicas com os parentes da área indígena.

Quanto ao português, essa língua é usada em todos os lugares, em repartições públicas (escolas, universidade, correios, banco etc.) e privadas (supermercado, lojas etc.) e, também, em momentos de interação com os amigos não indígenas e com os indígenas que já são monolíngues em português, por exemplo, os indígenas da região do Baixo Tapajós/PA. O uso da escrita em português ocorre 
mais no âmbito acadêmico para a elaboração de trabalhos de aproveitamento e também em grupos de WhatsApp das disciplinas, mas em menor uso, pois os consultantes dizem que ficam inseguros e com medo das críticas dos alunos não indígenas que possam surgir.

No que se refere à atitude linguística, a maioria dos entrevistados não manifestou em seu discurso atitudes de valorização da língua Wai Wai. A maioria alega que se comunica nessa língua mais por "costume". De modo geral, argumentam que não "esquecerão" a sua língua, conforme suas palavras: “eu não vou esquecer a língua do meu povo!”. Porém, observamos que alguns membros em situações de indagações sobre o léxico da língua Wai Wai, no espaço universitário, já estão com dificuldade de lembrar certas palavras, mas não se dão conta de que isso já demonstra o início de um processo de esquecimento. Poucos demonstraram um forte sentimento, atitudes de valorização da língua, embora sempre se referindo a ela como "minha língua" ou "nossa língua" e argumentando sobre a sua importância como um instrumento de fortalecimento cultural e linguístico do povo.

\subsubsection{Língua da comunicação com os filhos}

Dentre os participantes da pesquisa, sete são casados e têm filhos. Vejamos o uso que cada um desses consultantes faz das línguas de seu repertório na interação com os filhos e qual (-is) língua(s) as crianças usam em outros domínios que não o da família.

Caso 1 - filho da consultante 02: essa consultante é da etnia Wai Wai e seu cônjuge da etnia Hixkaryana. O casal tem um menino de seis anos, plurilíngue ativo em Wai Wai-Hixkaryana-Português. A língua Wai Wai aprendeu com sua mãe; a língua Hixkaryana aprendeu com seu pai; já a língua Portuguesa iniciou sua aquisição na escola formal. Quanto ao uso, interage com os adultos na língua que estiverem falando com ele. Com o pai, geralmente fala em Hixkaryana, com a mãe em Wai Wai, em Português, fala com os vizinhos e com os colegas da escola.

Caso 2 - filha do consultante 04: esse consultante é da etnia Wai Wai e encontra-se separado de sua esposa, sobre a qual preferiu não falar. Ele tem uma filha de três anos, que veio bebê para a cidade e é criada por ele e sua irmã. Segundo o pai a criança sabe se comunicar em Wai Wai e em Português. Porém, nesse lar, ele e sua irmã decidiram que se comunicariam apenas em português, a fim de melhorar suas habilidades comunicativas nessa língua. Essa decisão desfavorece a língua indígena, visto que os adultos já começam a ter dificuldade no léxico da língua Wai Wai e a criança, em fase de aquisição linguística, poderá não ter a chance de adquirir proficiência na língua do seu povo.

Caso 3 - filho da consultante 07: essa consultante é da etnia Wai Wai e seu cônjuge também. O casal tem um menino de dois anos e meio, que nasceu na 
cidade. Eles se comunicam com a criança em Wai Wai, que já fala um pouco nessa língua. Quanto ao português os pais dizem que o menino ainda não sabe se comunicar nela, mas conforme nossa observação, nos momentos de interação com ele, demonstra compreender o que é falado em português.

Caso 4 - filho do consultante 10: esse consultante é Wai Wai e sua esposa é Mundurukú (do Alto Tapajós). O casal tem um menino de 01 ano e 3 meses. Com a esposa se comunica em Português, mas ao falar com a criança, ele fala em Wai Wai e a mãe em Mundurukú. Nesse caso a criança está em processo de aquisição de duas línguas, simultaneamente, visto que já começa a entender e a pronunciar palavras nas duas línguas.

Caso 5 - filhos do consultante 13: o consultante 3 tem três filhos, mas somente a criança mais nova, uma menina de 02 anos reside com ele e a esposa (Wai Wai) em Santarém, os demais residem na aldeia Mapuera com os avós. Segundo ele a língua no domínio do lar, na cidade, é a Wai Wai, a qual sua filha entende e já começou a falar. Observamos que a criança também já compreende o que falado em português.

Caso 6 - filhos do consultante 14: esse consultante é da etnia Hixkaryana e sua esposa é da etnia Wai Wai. O casal têm dois filhos: uma menina de 11 anos e um menino de 02 anos. De acordo com o consultante, a língua da comunicação no domínio do lar é a Wai Wai. Porém, observamos que a interação dos pais com o filho menor se dava apenas em português e a criança respondia às indagações também nessa língua. Observamos também que a filha mais velha, embora apresente bilinguismo ativo em Wai Wai-Português ao interagir preferia responder em português. Tudo indica que a língua indígena esta sendo substituída pela portuguesa nessa família.

Caso 7 - filhos da consultante 17: essa consultante migrou para Santarém, em 2013, para cursar pedagogia na Ufopa. Ela se formou, mas decidiu não voltar para a aldeia, pois constituiu família com um indígena da etnia tupinambá, com quem teve 02 filhos. Embora seja plurilíngue em Wai Wai-HixkaryánaPortuguês, ela se comunica com os filhos e o esposo apenas em português, visto que todos eles são monolíngues nessa língua.

Considerando esses casos, observamos que há situação de aquisição simultânea de línguas pelos filhos da consultante 02 (caso 1) e do consultante 10 (caso 4). O primeiro, já com seis anos, adquiriu duas línguas ao mesmo tempo: a Wai Wai com a mãe e a Hixkaryana com o pai. O segundo está em fase de aquisição linguística: está aprendendo Wai Wai com o pai e seus parentes e Munduruku com sua mãe. De Heredia (1989) chama esse fenômeno de bilinguismo precoce, que ocorre na faixa etária de 0 a 5 anos, geralmente com filhos de casamentos mistos (etnias distintas), como esses. Nos casos 3 e 5 , notamos que os filhos estão aprendendo a falar primeiro na língua dos país, mas já conseguem compreender o português. No caso 2 e 6 , os filhos estão 
caminhando para o monolinguismo em português, pois há uma preferência pelo uso dessa língua na interação familiar. No último caso, o 7, apesar da mãe ser plurilíngue em Wai Wai-Hixkaryana-Português, os filhos não chegaram a aprender nenhuma língua indígena, são monolíngues em português. Aqui, merece destaque a variável constituição familiar como significativa para o status de monolinguismo dos filhos, pois segundo a consultante, o fato do esposo ser monolíngue em português foi o fator motivador para que ela preferisse se comunicar em casa, inclusive com os filhos, apenas em português, pois assim todos compreenderiam.

\section{Considerações finais}

Pôde-se caracterizar com este trabalho a situação sociolinguística dos Wai Wai residentes em Santarém/PA, analisando o mono- ou bi- ou plurilinguismo (bilinguismo individual, cf. De Heredia 1989) dos membros desse povo e o valor funcional (bilinguismo social, cf. Fishman 1964) das línguas que compõem o seu repertório linguístico.

Foram localizados 23 indígenas Wai Wai, sendo que apenas 17 aceitaram participar da pesquisa. São estudantes da Universidade Federal do Oeste do Pará, oriundos, em sua maioria, da aldeia Mapuera (T.I.Nhamunda-Mapuera), que em Santarém, vivem concentrados em bairros próximos à universidade onde estudam.

Constatamos que o repertório linguístico dos Wai Wai é bastante diversificado, pois todos os consultantes apresentam situações de pluri ou de bilinguismo ativo nas línguas indígenas de seu repertório linguístico, para as gerações nascidas na área indígena (os adultos). Além dessas línguas, faz parte do repertório linguístico dos Wai Wai, há várias gerações, o Português, no qual todos apresentam fluência, e o Inglês, para apenas um dos indígenas consultados, em função da presença de missionários americanos em suas terras.

Constatamos também que alguns pais não estão transmitindo sua língua indígena aos filhos, os quais estão caminhando para se tornarem monolíngues em Português (casos dos consultantes 4 e 14). A não transmissão da língua indígena aos filhos já denota uma atitude de não valorização desta, pois se sabe o peso que têm as atitudes dos locutores em relação a sua língua. De fato, a fidelidade linguística que os locutores emigrados mantêm com sua língua, cuja manifestação se dá "pelo uso que fazem dela entre familiares e amigos e por sua transmissão às crianças está evidentemente relacionada com as atitudes que eles desenvolvem em relação aos dois países representados simbolicamente por sua língua" (Heredia 1989, 178). No caso deste estudo, em relação à Terra Indígena e a cidade.

A vitalidade de uma língua depende do seu uso e da sua valorização pelos membros que as falam. Para isso, é necessário primeiramente que haja 
uma mudança de atitude em relação as línguas indígenas e planejar ações de fortalecimento. Somente assim os indígenas poderão manter suas línguas vivas no meio urbano.

Esperamos que as informações e as reflexões levantadas nesse trabalho contribuam para que os Wai Wai reflitam sobre a situação da sua língua primeira, alertando-os quanto à importância do seu fortalecimento no espaço urbano, pois, sendo a língua um forte elemento da identidade cultural de um povo, deve ser perpetuada para as gerações vindouras, se o grupo assim desejar. Em alinhamento com essa ideia, os resultados obtidos com este estudo alimentarão disciplinas dos cursos de graduação da UFOPA, principalmente aqueles frequentados por indígenas Wai Wai, assim como por indígenas de outras etnias, estimulando pesquisas dessa natureza a seram protagonizadas pelos próprios indígenas.

\section{Referências}

Bortoni-Ricardo, S. M. 2014. Manual de sociolinguística. São Paulo: Contexto, p. 13.

Cardozo, I. B.; Vale Jr. I. C. do. 2012. Etnozoneamento da Porção Paraense das Terras Indigenas Trombetas-Mapuera e Nhamundá-Mapuera. Porto Velho, Editora EDUFRO.

Carneiro, D. de S.; Peixoto, V. do N. 2015. Povos indígenas e diversidade linguística. In: Cultura e história dos povos indígenas no Brasil: Novas Contribuições ao ensino. Uberlândia, MG; RB Gráfica Digital Ereli.

Coelho, I. L. et al. 2015. Para conhecer sociolinguística. São Paulo: Contexto.

Comissão Pró-Índio; Centro Gaspar Garcia de Direitos Humanos. 2013. A Cidade como local de afirmação dos direitos. São Paulo, $1^{\mathrm{a}}$ ed.

Bagno, Marcos. 2017. Dicionário críticos de sociolinguística. São Paulo: Parábola Editorial.

De Heredia, C. 1989. Do bilinguismo ao falar bilíngue. In: Vermes, G. e J. Boutet (orgs.). Multilinguismo. Campinas: Unicamp, p.117-219.

Fishman, J. 1974. A Sociologia da Linguagem. In: Fonseca, M. S. V. \& Neves, M. F. (orgs). Sociolinguística. Rio de Janeiro: Eldorado.

Franceschini, D. do C. 2011. Línguas indígenas e português: contato ou conflito de línguas? Reflexões acerca da situação dos Mawé. In: Silva, S. de S. (Org.) Cenários de bilinguismo no Brasil. Coleção: Linguagem e Sociedade Vol.2. Campinas, SP: Pontes.

Grosjean, François. 2008. Bilinguismo Individual. In: Revista UFG. Ano X. $\mathrm{n}^{\circ} 5$. [Tradução de Heloísa Augusta Brito de Mello e Dilys Karen Rees].

IBGE (Instituto Brasileiro de Geografia e Estatística). 2012. Os indígenas no Censo Demográfico 2010: primeiras considerações com base no quesito cor ou raça. Rio de Janeiro: IBGE.

Lima, G. de O. S. et al. 2010. Sociolinguística. São Cristovão: UFS, Cesad. 
Melatti, J. C. 1994. Índios do Brasil. $7^{\text {a }}$ ed. São Paulo: Hucitec.

Pagotto, E. G. 2006. Sociolinguística.In: Pfeiffer, C. C.; Nunes, J. H. (Orgs.). Introdução às ciências da linguagem - Linguagem, História e Conhecimento. Campinas/SP: Pontes Editores.

Queiroz, R. C. de. 2015. Cosmologia e história waiwai e katxuyana: sobre os movimentos de fusão e dispersão dos povos (Yana). In: Grupioni, D. F. et al (Org.). Entre águas bravas e mansas: índios e quilombolas em Oriximiná. 1ed.São Paulo: Comissão Pró-índio de São Paulo; Iepé.

Rodrigues, A. D. 2013 Línguas indigenas brasileiras. Brasília, DF: Laboratório de Línguas Indígenas da UnB, p.14.

Santos, L. A. dos. 20016. Sociolinguística e línguas indígenas brasileiras. In: Mollica, M. C.; Ferrarezi, C. J. (Orgs.). Sociolinguistica, Sociolinguisticas: uma introdução. São Paulo: Ed. Contexto. 